九州大学学術情報リポジトリ

Kyushu University Institutional Repository

\title{
A Case Study of Rice Marketing in Selected Areas of Myanmar
}

Lwin, Hnin Yu

Deaprtment of Agricultural Economics, Yezin Agricultural University

Yutaka, Tomoyuki

Faculty of Agriculture, Kyushu University

Fukuda, Susumu

Faculty of Agriculture, Kyushu University

Kai, Satoshi

Faculty of Agriculture, Kyushu University

https://doi.org/10.5109/4725

出版情報：九州大学大学院農学研究院紀要. 51 (1)，pp.147-155，2006-02-01. Faculty of Agriculture, Kyushu University

バージョン :

権利関係 : 


\title{
A Case Study of Rice Marketing in Selected Areas of Myanmar
}

\author{
Hnin Yu LWIN 1 , Tomoyuki YUTAKA, Susumu FUKUDA \\ and Satoshi KAI*
}

\author{
Laboratory of Agricultural Marketing, Division of Industrial Organization of Agribusiness, \\ Department of Agricultural and Resource Economics, Faculty of Agriculture, \\ Kyushu University, Fukuoka 812-8581, Japan \\ (Received October 28, 2005 and accepted November 16, 2005)
}

\begin{abstract}
This paper evaluates the rice marketing channels and the interaction of market participants in selected areas of Myanmar. The main rice marketing channels in the studied sites indicate that almost all products of farmers flow to collectors and millers. Lack of formal cooperative structures, farmers support groups and growing market power of millers at the farm-gate level result that farmers possess low bargaining power in the trading of paddy and rice at the studied areas. Moreover news about price changes and relevant price-making forces in pertinent terminal market are generally obtained from informal sources. This indicates that the informal market information is dominant and plays an important role. Government should build-up the cooperatives not only to encourage the bargaining power of farmers at farm gate level, but also to accelerate the market intelligence of intermediaries in the rice marketing channel. Moreover, to solve the conflicting sources of information, a public market information center organized by government and non-profit rice trader's organization is needed to distribute reliable up-to-date market information effectively and efficiently.
\end{abstract}

\section{INTRODUCTION}

Myanmar still remains one of the developing countries and its economy mainly depends on agricultural production. Food cultivation for self-sufficiency and security is being always a priority issue. A considerable share of total export value occupied by Agriculture sector can contribute to the needs for the structural change of economy towards industrialization and modernization of the country.

Agricultural production value, calculated by fixed price of 1985 , increased from 19,470 million Kyats in 1990 to 33,658 million Kyats in 2001, equivalent to the average growth rate of 7.3 percent per year. Among agricultural products, rice is the most important export crop and is also designated as national crop to highlight its great importance as the main staple of Myanmar population. Therefore, an increase in its price can easily affect the consumers badly. Policy-makers are unable to deregulate the market as easily as the other agricultural commodities (for example pulses and beans).

With regard to rice production, Ayeyarwady, Bago, Yangon Divisions and Mon State situated at the lower part of Myanmar are the major rice producing and surplus areas of the country. The central part of the country consisting of Magway, Sagaing and Mandalay Division and Shan State are the deficit areas.

Hlegu Township in Yangon Division and Pathein Township in Ayeyarwady Division have been chosen as the study sites. Structured questionnaire were used to interview farmers and marketing intermediaries including assemblers, millers, local wholesalers and retailers. (Table 1) (Figure 1)

\footnotetext{
1 Department of Agricultural Economics, Yezin Agricultural University, Yezin, Myanmar.

* Corresponding author (E-mail: satokai@agr.kyushu-u.ac.jp)
}

Table 1. Number of interviewees in survey 2004

\begin{tabular}{lccc}
\hline & Hlegu Township & Pathein Township & Total \\
\hline Farmers & 28 & 32 & 60 \\
Middlemen & 13 & 17 & 30 \\
\hline
\end{tabular}

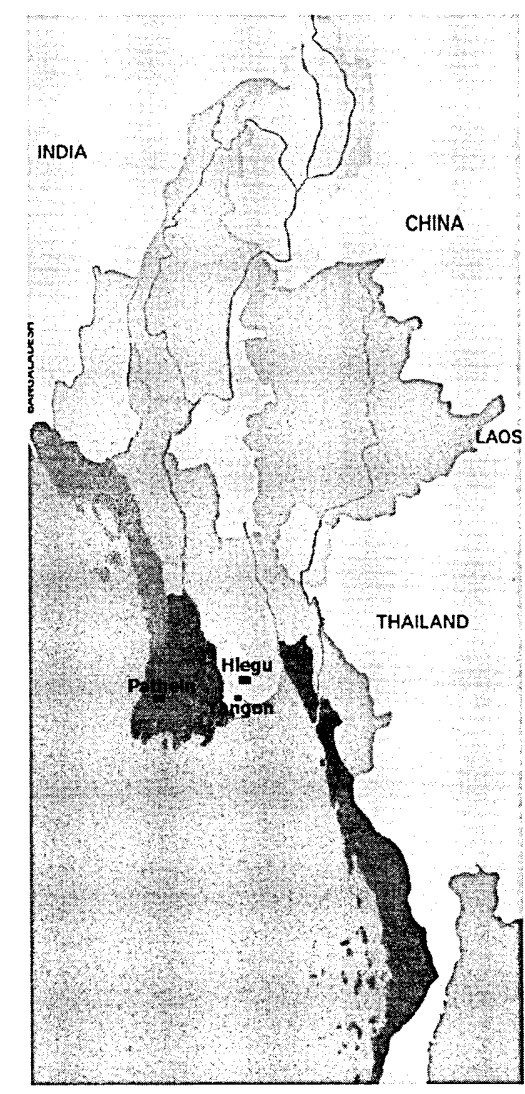

Fig. 1. Survey area in Myanmar 2004 
These two areas were selected in view of the following criteria:

1. The homogeneity of the study areas in terms of cropping system and socio-economic features of the farmers is the prime basis for selection of the study areas.

2. Both study sites are in the rice surplus regions and marketing channel can be explicitly examined by analyzing the existence and performance of market intermediaries.

The specific objectives of this study are as follows:

A. To identify the marketing channel and margin of rice marketing

B. To examine cropping patterns and marketing practices of rice farmers

C. To verify the activities of rice market intermediaries

Rice marketing in the study sites is a dynamic and complicated process of interaction among numerous market agents involved in the various channels of the system. A description of the channels and the dynamics between channels and market participants follows. Factors considered by farmers and traders as important in the marketing process are also discussed.

\section{MARKETING CHANNELS IN THE STUDIED AREAS}

Rice distribution system is a bit different in these two study sites. According to the survey, there are 4 main rice marketing channels in Hlegu area. All collectors in this area serve as agents of millers. The first three main marketing channels show that almost all of farmers' products flow to the millers and consequently, the market power of miller is boosting at the farm-gate level. Moreover, because of the business integration of millers doing milling and trading of rice activities simultaneously by investing large amount of capital, trading of rice as local wholesaler activities is diminishing in Hlegu area. Only existence of small and medium mills can give the chance to the consumers to buy rice directly form the millers even while large scale millers do not prefer to do such kind of transaction. (Figure 2)

In Pathein area, almost all of farm products also flow to millers who have the market power at farm-gate level.

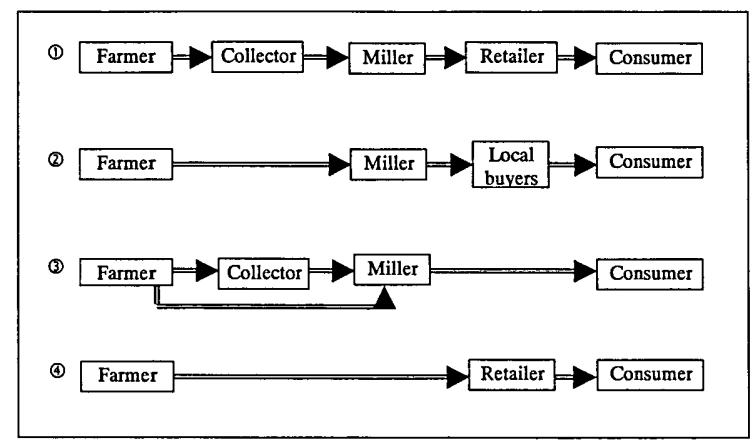

Fig. 2. Main rice marketing channel in Hlegu Township Source: Individual survey 2004
As Pathien area is located in the largest rice producing area, several intermediaries are participating in the rice marketing channel and interstate trading of rice is occurred by sending surplus to Yangon and other local markets. Even millers do marketing activities with huge amount of investment, local wholesalers' trading of rice by buying rice from mill and sending to Yangon and other local markets also play a main role. On the other hand, the existence of medium and large mills, consumers have no chance to buy rice directly from the mills for their home consumption. Therefore, retailers also play a key role in this marketing channel. (Figure 3)

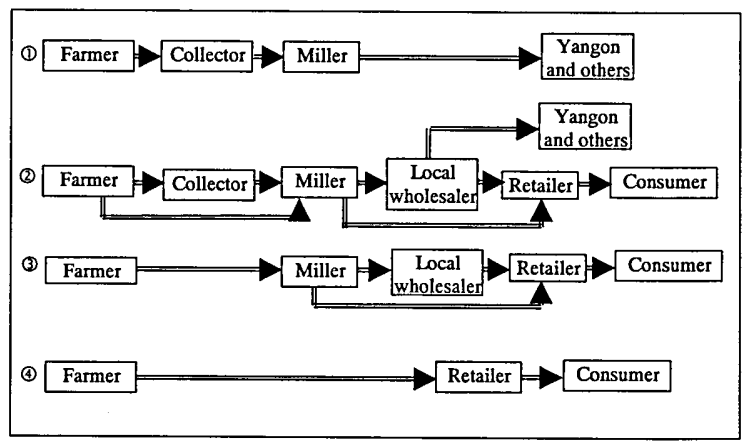

Fig. 3. Main rice marketing channel in Pathein Township Source: Individual survey 2004

\section{MARKETING COST AND MARGIN OF SOME AGENTS}

The services of various agencies constituting a marketing channel are remunerated out of the marketing "margin". This term used in this study is the difference between the price paid to the first seller and that paid by the final buyer.

Marketing cost and marketing margin are calculated for some main agents such as collectors, small, medium and large scale millers, local wholesalers and retailers in the rice marketing channel. Because of the lack of capital and paddy and rice price fluctuation, collectors in this study serve as the agents for the millers. Therefore, marketing margin of the collectors is the commission fees for buying paddy.

As already mentioned, the commodity types handled by the middlemen are different in the rice marketing channel as paddy in collectors and millers and rice in others. The percentage of profit per cost price indicator (return on investment) is used in this study in order to compare their achievement in the marketing channel.

Some millers provide milling service only for farmers and traders while most millers purchase paddy either directly from farmers and collectors. Processing and selling business of millers could receive higher net margin than that of other intermediaries. The percentage of profit per cost price is also high in the millers. Among millers, large-scaled millers attain highest profit per cost price and surprisingly small-scaled millers get higher profit than medium-scaled millers. 
Table 2. Marketing cost, marketing margin and profit of some agents

\begin{tabular}{|c|c|c|c|c|c|}
\hline Collector & Unit & \multicolumn{2}{|c|}{ Hlegu } & \multicolumn{2}{|c|}{ Pathein } \\
\hline Buying price of paddy & Kyats/ton & & 43137.0 & & 50326.5 \\
\hline Commission price per ton of paddy & Kyats/ton & & 958.6 & & 479.3 \\
\hline Cost Price & Kyats/ton & & 44095.6 & & 50805.8 \\
\hline Selling price per ton of paddy & Kyats/ton & & 44095.6 & & 50805.8 \\
\hline Marketing margin & Kyats/ton & & 958.6 & & 479.3 \\
\hline Profit per ton of paddy & Kyats/ton & & 958.6 & & 479.3 \\
\hline Profit per cost price & $\%$ & & 2.2 & & 0.9 \\
\hline \multirow{2}{*}{ Miller } & & \multicolumn{2}{|c|}{ Hlegu } & \multicolumn{2}{|c|}{ Pathein } \\
\hline & Unit & small & medium & medium & large \\
\hline Buying price of paddy & Kyats/ton & 43137.0 & 43137.0 & 50326.5 & 50326.5 \\
\hline Marketing cost & Kyats/ton & 1858.3 & 2406.6 & 3380.5 & 3620.2 \\
\hline Milling cost & Kyats/ton & 3972.4 & 4481.3 & 4069.3 & 1001.9 \\
\hline Commission service & Kyats/ton & 0.0 & 958.6 & 479.3 & 479.3 \\
\hline Total cost & Kyats/ton & 5830.7 & 7846.5 & 7929.1 & 5101.4 \\
\hline Cost Price & Kyats/ton & 48967.7 & 50983.5 & 58255.6 & 55427.9 \\
\hline Selling price of paddy & Kyats/ton & 52800.0 & 52800.0 & 60750.0 & 60750.0 \\
\hline Marketing margin & Kyats/ton & 9663.0 & 9663.0 & 10423.5 & 10423.5 \\
\hline Profit per ton of paddy & Kyats/ton & 3832.4 & 1816.5 & 2494.4 & 5322.1 \\
\hline Profit per cost price & $\%$ & 7.8 & 3.6 & 4.3 & 9.6 \\
\hline Local wholesaler & Unit & \multicolumn{2}{|c|}{ Hlegu } & \multicolumn{2}{|c|}{ Pathein } \\
\hline Buying price of rice & Kyats/ton & \multicolumn{2}{|r|}{ n.a } & & 99960.0 \\
\hline Marketing cost & Kyats/ton & \multicolumn{2}{|r|}{ n.a } & & 2013.2 \\
\hline Cost Price & Kyats/ton & \multicolumn{2}{|r|}{ n.a } & & 101973.2 \\
\hline Selling price rice & Kyats/ton & \multicolumn{2}{|r|}{ n.a } & & 103880.0 \\
\hline Marketing margin & Kyats/ton & \multicolumn{2}{|r|}{ n.a } & & 3920.0 \\
\hline Profit & Kyats/ton & \multicolumn{2}{|r|}{ n.a } & & 1906.8 \\
\hline Profit per cost price & $\%$ & \multicolumn{2}{|r|}{ n.a } & & 1.9 \\
\hline Retailer & Unit & \multicolumn{2}{|c|}{ Hlegu } & \multicolumn{2}{|c|}{ Pathein } \\
\hline Average buying price of rice & Kyats/ton & & 91728.0 & & 99960.0 \\
\hline Marketing cost & Kyats/ton & & 3681.9 & & 2940.0 \\
\hline Cost price & Kyats/ton & & 95409.9 & & 102900.0 \\
\hline Average selling price of rice & Kyats/ton & & 101236.4 & & 105855.7 \\
\hline Marketing margin & Kyats/ton & & 9508.4 & & 5895.7 \\
\hline Profit & Kyats/ton & & 5826.5 & & 2955.7 \\
\hline Profit per cost price & $\%$ & & 6.1 & & 2.9 \\
\hline
\end{tabular}

Source: Individual Interviews 2004

This could be explained that, using fuel-save-type milling machines (boiler engine) and huge amounts of capital investment can create the highest profit per cost price ratio for the large-scale miller. Not using the agents (commissioner) for buying paddy supports small-scaled mill that gets the chance to exploit the profit by operating the business in appropriate scale. Although the rice millers obtain the highest marketing margin, they also incur the highest marketing cost in terms of payment for drying, storing, manufacturing, and other service costs. Local wholesalers get a profit as a percentage of the cost price (1.9 percent) and retailers obtain a relatively high profit as 6.1 percent. (Table 2)

\section{GENERAL INFORMATION AND MARKETING PRACTICES OF RICE FARMERS}

Farmers in the study sites are classified according to the farm size as small (1-10 acres), medium $(>10-20$ acres) and large ( $>20$ acres). Results from the survey revealed that most head of households are male and have farming experience averaging 29 to 31.5 years. About 85.7 to 96.9 percent of farmers inherited the land from their forefathers and 78.6 to 84.4 percent of farmers are the full time farmers. (Table 3 )

Concerning the crop rotation pattern for one year of the study sites, monsoon rice cultivation area is 64.6 to 71.2 percent of the crop cultivation area. While pulses area is 7.3 percent of the total crop cultivation area in Hlegu Township, all farmers in Pathein township grow only monsoon rice and summer rice crop. In both study sites, the monsoon crop is seeded during May to September and harvested from November to January. The summer crop is seeded from November to February and harvested from March to May. (Table 4)

Traditionally farmers are not the owners of the Mills. When the harvest has ended, the farmers will use rented mills for about 250 to 300 Kyats per 1 bag of rice. Farmers then sell either paddy or rice. Farmers will keep part of the milled harvest as home consumption and the rest will be sold either to traders or to the millers. Paddy will also be sold at this time to traders. 
53.6 percent of Hlegu farmers and 68.8 percent of Pathein farmers sell only paddy and 28.6 percent in Hlegu and 9.4 percent in Pathein sell rice. 17.9 percent of Hlegu farmers and 21.9 percent of Pathein farmers sell both paddy and rice. (Table 5)

16.7 percent of large-scaled Hlegu farmers and 8.3 percent of medium-scaled Pathein farmers have the chance to sell their rice to rice shop directly. However, selling paddy to a collector is in high proportion as 59.3 percent in Hlegu township and 65.6 percent in Pathein township. (Table 6)
Price discovery refers to the process of interaction among market agents, via various pricing mechanisms, in arriving at a transaction price (Kohls and Uhl, 2002). As in other developing economies, market information is relayed and transmitted across markets inexpensively, by word of mouth. News about price changes and relevant price-making forces in any pertinent terminal market are generally obtained from informal sources.

Local collectors are the main source of price information. About 39.3 percent of farmers in Hlegu area and 44.4 percent of farmers in Pathein area usually get

Table 3. General information of farm household heads

\begin{tabular}{|c|c|c|c|c|c|c|c|c|c|}
\hline \multirow{2}{*}{ Indicator } & \multirow{2}{*}{ Unit } & \multicolumn{4}{|c|}{ Hlegu Township } & \multicolumn{4}{|c|}{ Pathein Township } \\
\hline & & small & medium & large & avg & small & medium & large & avg \\
\hline Entry farming & Year & 35.1 & 26.3 & 28.5 & 31.5 & 31.4 & 30.4 & 22.3 & 29.0 \\
\hline Male HHH & $\%$ & 100.0 & 100.0 & 100.0 & 100.0 & 92.3 & 100.0 & 100.0 & 96.9 \\
\hline Farm successor & $\%$ & 86.7 & 85.7 & 83.3 & 85.7 & 100.0 & 91.7 & 100.0 & 96.9 \\
\hline Full time farmer & $\%$ & 73.3 & 85.7 & 83.3 & 78.6 & 84.6 & 75.0 & 100.0 & 84.4 \\
\hline
\end{tabular}

Source: Individual Interviews of Farmers 2004

Table 4. Cropping pattern

(Unit $=\%)$

\begin{tabular}{|c|c|c|c|c|c|c|c|c|}
\hline \multirow{2}{*}{ Indicator } & \multicolumn{4}{|c|}{ Hlegu Township } & \multicolumn{4}{|c|}{ Pathein Township } \\
\hline & small & medium & large & avg & small & medium & large & avg \\
\hline Monsoon rice area & 71.0 & 64.1 & 74.3 & 71.2 & 59.3 & 63.9 & 68.1 & 64.6 \\
\hline Summer rice area & 20.6 & 17.9 & 23.3 & 21.5 & 40.7 & 36.1 & 31.9 & 35.4 \\
\hline Pulses area & 8.4 & 17.9 & 2.4 & 7.3 & 0.0 & 0.0 & 0.0 & 0.0 \\
\hline Total & 100.0 & 100.0 & 100.0 & 100.0 & 100.0 & 100.0 & 100.0 & 100.0 \\
\hline
\end{tabular}

Source: Individual Interviews of Farmers 2004

Table 5. Differentiation of selling commodity type

(Unit=\%)

\begin{tabular}{|c|c|c|c|c|c|c|c|c|}
\hline \multirow{2}{*}{ Activity } & \multicolumn{4}{|c|}{ Hlegu Township } & \multicolumn{4}{|c|}{ Pathein Township } \\
\hline & small & medium & large & avg & small & medium & large & avg \\
\hline Sell paddy & 66.7 & 42.9 & 33.3 & 53.6 & 84.6 & 66.7 & 42.9 & 68.8 \\
\hline Sell rice & 20.0 & 57.1 & 16.7 & 28.6 & 7.7 & 0.0 & 28.6 & 9.4 \\
\hline Sell paddy and rice & 13.3 & 0.0 & 50.0 & 17.9 & 7.7 & 33.3 & 28.6 & 21.9 \\
\hline Total & 100.0 & 100.0 & 100.0 & 100.0 & 100.0 & 100.0 & 100.0 & 100.0 \\
\hline
\end{tabular}

Source: Individual Interviews of Farmers 2004

Table 6. Use of middlemen in marketing

(Unit=\%)

\begin{tabular}{|c|c|c|c|c|c|c|c|c|}
\hline \multirow{2}{*}{ Activity } & \multicolumn{4}{|c|}{ Hlegu Township } & \multicolumn{4}{|c|}{ Pathein Township } \\
\hline & small & medium & large & avg & small & medium & large & avg \\
\hline rice shop & 0.0 & 0.0 & 16.7 & 3.7 & 0.0 & 8.3 & 0.0 & 3.1 \\
\hline collector & 73.3 & 50.0 & 33.3 & 59.3 & 84.6 & 50.0 & 57.1 & 65.6 \\
\hline miller & 26.7 & 50.0 & 33.3 & 33.3 & 7.7 & 0.0 & 14.3 & 6.3 \\
\hline collector and miller & 0.0 & 0.0 & 16.7 & 3.7 & 7.7 & 41.7 & 28.6 & 25.0 \\
\hline Total & 100.0 & 100.0 & 100.0 & 100.0 & 100.0 & 100.0 & 100.0 & 100.0 \\
\hline
\end{tabular}

Source: Individual Interviews of Farmers 2004 
Table 7. Getting price information of farmers

(Unit=\%)

\begin{tabular}{|c|c|c|c|c|c|c|c|c|}
\hline \multirow{2}{*}{ Activity } & \multicolumn{4}{|c|}{ Hlegu Township } & \multicolumn{4}{|c|}{ Pathein Township } \\
\hline & small & medium & large & avg & small & medium & large & avg \\
\hline Neighborhood & 13.3 & 28.6 & 0.0 & 14.3 & 54.5 & 10.0 & 16.7 & 29.6 \\
\hline Collector & 53.3 & 28.6 & 16.7 & 39.3 & 36.4 & 50.0 & 50.0 & 44.4 \\
\hline Miller & 26.7 & 28.6 & 16.7 & 25.0 & 0.0 & 0.0 & 0.0 & 0.0 \\
\hline Rice shop & 0.0 & 0.0 & 16.7 & 3.6 & 0.0 & 0.0 & 0.0 & 0.0 \\
\hline Miller and collector & 6.7 & 14.3 & 50.0 & 17.9 & 9.1 & 40.0 & 33.3 & 25.9 \\
\hline Total & 100.0 & 100.0 & 100.0 & 100.0 & 100.0 & 100.0 & 100.0 & 100.0 \\
\hline
\end{tabular}

Source: Individual Interviews of Farmers 2004

Table 8. Price Formation Process

(Unit=\%)

\begin{tabular}{|c|c|c|c|c|c|c|c|c|}
\hline \multirow{2}{*}{ Activity } & \multicolumn{4}{|c|}{ Hlegu Township } & \multicolumn{4}{|c|}{ Pathein Township } \\
\hline & small & medium & large & avg & small & medium & large & avg \\
\hline collector & 57.1 & 40.0 & 40.0 & 47.1 & 50.0 & 44.4 & 40.0 & 45.8 \\
\hline miller & 42.9 & 40.0 & 40.0 & 41.2 & 20.0 & 11.1 & 60.0 & 25.0 \\
\hline farmer & 0.0 & 20.0 & 0.0 & 5.9 & 0.0 & 0.0 & 0.0 & 0.0 \\
\hline rice shop & 0.0 & 0.0 & 20.0 & 5.9 & 0.0 & 0.0 & 0.0 & 0.0 \\
\hline Negotiation & 0.0 & 0.0 & 0.0 & 0.0 & 30.0 & 44.4 & 0.0 & 29.2 \\
\hline total & 100.0 & 100.0 & 100.0 & 100.0 & 100.0 & 100.0 & 100.0 & 100.0 \\
\hline
\end{tabular}

Source: Individual Interviews of Farmers 2004

the price information from local brokers. 17.9 percent of Hlegu farmers and 25.9 percent of Pathein farmers inquire the selling price more than one sources especially from millers and collectors. This indicates that the informal information on market is dominant and plays an important role. Farmers do not rely on formal information sources provided by the Government. (Table 7)

Generally, rice prices are set privately (individual), on the spot through negotiation between farmers and traders. In setting the rice price in Hlegu region, about 47.1 percent of farmer respondents indicated that the collectors setting the price, while about 41.2 percent reported the miller as offering the price and only about 5.9 percent described as themselves offering price for traders. In Pathein area, 45.8 percent of farmers accepted the price set by collectors and 29.2 percent indicated a negotiation as the process for setting the price with the traders. (Table 8)

\section{INFORMATION OF MILLERS AND COLLECTORS}

\section{General profiles of millers and collectors}

Local millers are categorized by size. Large mills have the capacity of up to 20 tons per day. Medium mills process over 5 tons to 19 tons per day and small mills handle less than 5 tons per day.

Most of the mills operated in Hlegu area are small and medium size and most are medium and large size in Pathein area. Male household headed mills are mostly found in both areas. 40 percent of millers in Hlegu have high school level education and impressively 66.7 percent of millers in Pathein got the bachelors degree. Most millers have 7 years business experience in Hlegu area and 9 years experience in Pathein area. (Table 9)

The education level of the household head of collectors is 100 percent secondary level in Hlegu and is 0 percent secondary level in Pathein. Most of them have done their business with 8.0 years of working experience

Table 9. General information of collectors and millers

\begin{tabular}{|c|c|c|c|c|c|c|c|c|c|}
\hline \multirow{3}{*}{ Indicator } & \multirow{3}{*}{ Unit } & \multicolumn{4}{|c|}{ Hlegu Township } & \multicolumn{4}{|c|}{ Pathein Township } \\
\hline & & \multicolumn{3}{|c|}{ Miller } & \multirow{2}{*}{ Collector } & \multicolumn{3}{|c|}{ Miller } & \multirow{2}{*}{ Collector } \\
\hline & & small & medium & total & & medium & large & total & \\
\hline male HHH & $\%$ & 100.0 & 66.7 & 80.0 & 100.0 & 0.0 & 66.7 & 33.3 & 100.0 \\
\hline $\begin{array}{l}\text { Education level } \\
\text { primary }\end{array}$ & $\%$ & 500 & 0.0 & 20.0 & 0.0 & 0.0 & 0.0 & 0.0 & 100.0 \\
\hline secondary & $\%$ & 50.0 & 0.0 & 20.0 & 100.0 & 0.0 & 0.0 & 0.0 & 0.0 \\
\hline high school & $\%$ & 0.0 & 66.7 & 40.0 & 0.0 & 0.0 & 66.7 & 33.3 & 0.0 \\
\hline educated & $\%$ & 0.0 & 33.3 & 20.0 & 0.0 & 100.0 & 33.3 & 66.7 & 0.0 \\
\hline business experience & Year & 4.0 & 9.0 & 7.0 & 8.0 & 8.7 & 9.3 & 9.0 & 6.0 \\
\hline
\end{tabular}

Source: Individual Interviews of Millers and collectors 2004 
Table 10. Summary activities of collectors

\begin{tabular}{|c|c|c|}
\hline Indicator & Hlegu & Pathein \\
\hline total purchase paddy (ton/year) & 166.9 & 417.3 \\
\hline \multicolumn{3}{|c|}{ Methods used to buy paddy (\%) } \\
\hline looking for farmers & 100.0 & 100.0 \\
\hline farmers come & 0.0 & 0.0 \\
\hline \multicolumn{3}{|c|}{ Source of information (\%) } \\
\hline miller & 100.0 & 100.0 \\
\hline other traders & 0.0 & 0.0 \\
\hline \multicolumn{3}{|c|}{ Important factors of paddy pricing (\%) } \\
\hline grain quality & 100.0 & 100.0 \\
\hline others & 0.0 & 0.0 \\
\hline \multicolumn{3}{|c|}{ To whom collector sell paddy (\%) } \\
\hline miller & 100.0 & 100.0 \\
\hline other traders & 0.0 & 0.0 \\
\hline \multicolumn{3}{|c|}{ Type of service (\%) } \\
\hline commission & 100.0 & 100.0 \\
\hline with profit & 0.0 & 0.0 \\
\hline commission fees (Kyats/ton) & 958.6 & 479.3 \\
\hline
\end{tabular}

Source: Individual Interviews of Collectors 2004

in Hlegu and with 6.0 years of experience in Pathein.

\section{Summary activities of collectors}

Traditionally, there are 2 types of collectors. The first type of collectors directly buy paddy from farmers and carry paddy to the millers or to their storage places, either they sell back paddy to millers or other collectors with profit. Second type of collectors (commission middlemen for the miller) buy paddy from farmers with the decided price by the millers and send to the mills getting the commission fees from the millers. According to the survey, first type collectors were gradually disappearing because of rice price fluctuation and the growing marketing power of millers in these areas. (Table 10)

On average 166.9 tons of paddy are purchased by collectors per year in Hlegu area while in Pathein area is more than twice with 417.3 tons per year. All collectors serve as commission men to purchase the commodity for the millers. Therefore, the price information is mainly obtained from the millers. Commission fee is two times higher in the Hlegu area with 958.6 Kyats per ton while 479.3 Kyats per ton in Pathein area.

\section{Activities of rice milling household}

The large-scale and medium-scale mills mainly provide milling service for farmers, traders and some collectors. Additionally they also buy paddy from farmers and collectors, process it and sell rice to the wholesalers and traders. The small-scale plants, which are numerous in numbers, are widely spread in the rice producing area. Generally, almost all of them are privately owned and mainly process paddy from their own farm and for the neighborhood farmers for their own consumption need.

Depending on the scale of mill, the mill capacity varies from 704 to 5,206 tons per year. Nearly all mills operate at full capacity mainly during the harvesting season and operate just a few hours at the seeding season. After harvesting of monsoon crop November to February
Table 11. Main activities and behavior of local millers

\begin{tabular}{ccccccc}
\hline \multirow{2}{*}{ Indicator } & \multicolumn{2}{c}{ Hlegu Township } & & \multicolumn{2}{c}{ Pathien Township } \\
\cline { 2 - 3 } \cline { 5 - 6 } \cline { 5 - 6 } & small & medium & & medium & large \\
\hline $\begin{array}{c}\text { Milling capacity } \\
\text { (tons/year) }\end{array}$ & 704.0 & 2201.0 & & 2324.0 & 5206.0 \\
$\begin{array}{c}\text { Storage capacity } \\
\text { (ton) }\end{array}$ & 0.0 & 31.3 & & 62.6 & 166.9 \\
$\begin{array}{c}\text { Holding period } \\
\text { (month) }\end{array}$ & 0.0 & 3.0 & & 3.0 & 3.0 \\
$\begin{array}{c}\text { Conversion rate } \\
(\%)\end{array}$ & 61.1 & 61.1 & & 61.1 & 61.1 \\
\hline
\end{tabular}

Source: Individual Interviews of Millers 2004

and that of summer crop March to May are the busiest months. But during the monsoon crop-planting season, there are few jobs for the millers. The conversion ratio between paddy and white rice is not varied between small and large scale mills. (Table 11)

Milling cost per ton on average is lowest in large mills and the cost of labor occupies the largest proportion of overall processing costs. In the small and medium scale mills fuel and oil expenses have the highest processing costs. This is due to the different types of machinery; large scale mills in Pathein area use boiler engines, which do not have the high cost in fuel and oil that lead to low cost in processing. However, tax payment by the large mill is relatively high in comparison to other mills. (Table 12)

According to survey the main obstacles for rice milling and processing households are: restriction of surface area used for production, low level operation of machine, and lack of capital. Almost all small-scaled rice mills in Hlegu area sell their products to consumers and retailers. Medium size mills in both areas mainly sell rice to local customers including retailers and other small traders. About 66.7 percent of large millers in Pathein area send their products to Yangon wholesaler. (Table 13) 
Table 12. Cost of milling and milling fees of paddy

$($ Unit $=$ Kyats/ton $)$

\begin{tabular}{|c|c|c|c|c|c|c|c|c|}
\hline \multirow{2}{*}{ Item } & \multicolumn{4}{|c|}{ Hlegu Township } & \multicolumn{4}{|c|}{ Pathein Township } \\
\hline & small & $\%$ & medium & $\%$ & medium & $\%$ & large & $\%$ \\
\hline Fuel and oil & 2827.9 & 71.2 & 2939.7 & 65.6 & 2564.3 & 63.0 & 245.7 & 24.5 \\
\hline Spare parts & 535.4 & 13.5 & 846.0 & 18.9 & 699.7 & 17.2 & 176.4 & 17.6 \\
\hline Maintenance cost & 47.9 & 1.2 & 71.9 & 1.6 & 26.1 & 0.6 & 12.0 & 1.2 \\
\hline Labor & 532.6 & 13.4 & 613.4 & 13.7 & 753.0 & 18.5 & 529.9 & 52.9 \\
\hline $\operatorname{Tax}$ & 28.6 & 0.7 & 10.3 & 0.2 & 26.3 & 0.6 & 38.0 & 3.8 \\
\hline Total & 3972.4 & 100.0 & 4481.3 & 100.0 & 4069.3 & 100.0 & 1001.9 & 100.0 \\
\hline Milling fees & 4313.7 & & 5221.7 & & 4313.7 & & 3594.8 & \\
\hline
\end{tabular}

Source: Individual Interviews of Millers 2004

Table 13. Selling activity of millers

(Unit=\%)

\begin{tabular}{lrrrrrrrr}
\hline \multirow{2}{*}{ Type } & \multicolumn{3}{c}{ Hlegu Township } & & \multicolumn{3}{c}{ Pathein Township } \\
\cline { 2 - 3 } \cline { 7 - 9 } & small & medium & avg & & medium & large & avg \\
\hline consumers & 50.0 & 0.0 & 20.0 & & 0.0 & 0.0 & 0.0 \\
retailers & 50.0 & 33.3 & 40.0 & & 0.0 & 0.0 & 0.0 \\
local customers & 0.0 & 66.7 & 40.0 & & 50.0 & 33.3 & 42.9 \\
Yangon and other places & 0.0 & 0.0 & 0.0 & & 50.0 & 66.7 & 57.1 \\
\hline total & 100.0 & 100.0 & 100.0 & & 100.0 & 100.0 & 100.0 \\
\hline
\end{tabular}

Source: Individual Interviews of Millers 2004

Table 14. Getting Price Information of millers

(Unit $=\%$ )

\begin{tabular}{lrrrrrrrr}
\hline \multirow{2}{*}{ Activity } & \multicolumn{3}{c}{ Hlegu Township } & & \multicolumn{3}{c}{ Pathein Township } \\
\cline { 2 - 3 } \cline { 7 - 9 } & small & medium & avg & & medium & large & avg \\
\hline Local market & 100.0 & 0.0 & 50.0 & & 33.3 & 0.0 & 16.7 \\
Other mill & 0.0 & 0.0 & 0.0 & & 33.3 & 0.0 & 16.7 \\
Yangon market & 0.0 & 100.0 & 50.0 & & 33.3 & 100.0 & 66.7 \\
\hline total & 100.0 & 100.0 & 100.0 & & 100.0 & 100.0 & 100.0 \\
\hline
\end{tabular}

Source: Individual Interviews of Millers 2004

In Hlegu area, 100 percent of small mills usually get the price information from local market while medium mills get it from Yangon market. All of the large mills in Pathein area contact Yangon market for rice price information while only 33.3 percent of medium mills use Yangon market rice price. (Table 14)

\section{MARKETING ACTIVITIES OF LOCAL WHOLESALERS}

Local wholesalers are the main intermediaries and usually operate a large scale on their business activities. Wholesalers frequently report the information of buying and selling prices to other wholesalers, millers and retailers. Therefore, wholesalers also play a key role in the distribution of rice price information in local area. However, local wholesalers in the Hlegu area are disappearing due to the fact of increasing millers' market power by doing milling and rice trading simultaneously.

Local wholesalers in Pathein area are also classified into 3 types depending on the amount of working capi-
Table 15. General Profile of Local wholesalers (Pathein)

\begin{tabular}{lcrrrr}
\hline \multicolumn{1}{c}{ Indicator } & unit & Small & Medium & Large & Total \\
\hline male HHH & $\%$ & 100.0 & 100.0 & 50.0 & 85.7 \\
Education level & & & & & \\
primary & $\%$ & 0.0 & 0.0 & 0.0 & 0.0 \\
secondary & $\%$ & 0.0 & 0.0 & 0.0 & 0.0 \\
high school & $\%$ & 33.3 & 50.0 & 50.0 & 42.9 \\
educated & $\%$ & 66.7 & 50.0 & 50.0 & 57.1 \\
Business experience & Year & 11.0 & 4.0 & 16.5 & 10.6 \\
\hline
\end{tabular}

Source: Individual Interviews of Local Wholesalers 2004

tal. Small scale wholesaler occupies less than 10 million Kyats working capital; medium scale owns 10-20 million Kyats working capital and large scale runs the business with over 20 million Kyats.

Almost all are male headed business except in the case of large scale. Education level is a high as usual case which the businessmen usually accompany by a high education level. Even in small scale 66.7 percent of wholesalers got the bachelor degree and 50 percent 
Table 16. Business of local wholesalers

$($ Unit $=\%)$

\begin{tabular}{lrrrc}
\hline Activities & small & medium & large & avg \\
\hline Trading paddy and rice & 66.7 & 0.0 & 50.0 & 42.9 \\
Trading rice & 33.3 & 100.0 & 50.0 & 57.1 \\
\hline Total & 100.0 & 100.0 & 100.0 & 100.0 \\
\hline Sending commodities to Yangon and other local area & 66.7 & 0.0 & 50.0 & 42.9 \\
Sending commodities to Yangon only & 0.0 & 100.0 & 50.0 & 42.9 \\
Sending commodities to Local area only & 33.3 & 0.0 & 0.0 & 14.3 \\
\hline Total & 100.0 & 100.0 & 100.0 & 100.0 \\
\hline
\end{tabular}

Source: Individual Interviews of Local Wholesalers 2004
Table 17. Other activities of local wholesalers $\quad$ (Unit $=\%$ )

\begin{tabular}{lccrc}
\hline \multicolumn{1}{c}{ Activity } & Small & Medium & Large & average \\
\hline Participation in Wholesaler & 100.0 & 100.0 & 100.0 & 100.0 \\
$\quad$ association & & & & \\
Getting price information & & & & \\
Yangon market & 66.7 & 100.0 & 100.0 & 85.7 \\
Other merchant & 33.3 & 0.0 & 0.0 & 14.3 \\
\hline total & 100.0 & 100.0 & 100.0 & 100.0 \\
\hline
\end{tabular}

Source: Individual Interviews of Local Wholesalers 2004

Table 18. General Profile of retailers

\begin{tabular}{lcccc}
\hline \multicolumn{1}{c}{ Indicator } & Unit & $\begin{array}{c}\text { Hlegu } \\
\text { Township }\end{array}$ & $\begin{array}{c}\text { Pathein } \\
\text { Township }\end{array}$ & Avg \\
\hline Gender of HHH & $\%$ & & & \\
male & 50.0 & 66.7 & 62.5 \\
Education level & & & & \\
primary & $\%$ & 16.7 & 33.3 & 22.2 \\
secondary & $\%$ & 16.7 & 33.3 & 22.2 \\
high school & $\%$ & 33.3 & 33.3 & 33.3 \\
educated & $\%$ & 33.3 & 0.0 & 22.2 \\
Business experience & Year & 8.0 & 5.0 & 7.0 \\
Family size & Person & 3.6 & 6.3 & 4.6 \\
\hline
\end{tabular}

Source: Individual Interviews of Retailers 2004

Table 19. Buying activities of retailers

(Unit=\%)

\begin{tabular}{lcc}
\hline \multicolumn{1}{c}{ Source } & Hlegu Township & Pathein Township \\
\hline local farmer & 27.3 & 33.3 \\
millers & 18.2 & 66.7 \\
local wholesaler & 0.0 & 0.0 \\
central wholesaler & 54.6 & 0.0 \\
\hline total & 100.0 & 100.0 \\
\hline
\end{tabular}

Source: Individual Interviews of Retailers 2004

each in middle and large scale. Business experience is highest in the large scale with 16.5 years. (Table 15)

Local wholesalers handle the commodities in two ways; one way is as only the trading of rice and others integrate the buying of paddy, processing and then selling. On average, 42.9 percent of wholesalers use the integration method and 57.1 percent of them use the rice trading method. About 42.9 percent of wholesalers send commodities to Yangon and other areas while only 14.3 percent of them send commodities to local area only. (Table 16)

All local wholesalers are members of the rice wholesaler association. About 85.7 percent usually get the price information from Yangon Center market and only 14.3 percent get from other merchants. Cooking rice quality is important in setting rice prices of Japonica variety with color and content of broken rice as the main factors in deciding the price of hard variety. According to the survey, the smooth trade flow and enough capital investment are the major factors for the rice marketing improvement. Rice price is fluctuates more than the paddy price and it is difficult for them to adjust accordingly. (Table 17)

\section{MARKETING ACTIVITIES OF RETAILERS}

Retailers are the last or final intermediaries in the marketing channel through which rice reaches the consumers. They are reported on buying rice from local wholesalers or millers and transporting to their shop by trishaw or a rental car. There is no price negotiation between retailer and wholesaler or miller in order to supply rice, retailer usually buy rice with market price and set the selling price depends on the buying rice price and their expected market margin. Some characteristic and behavior of this group is presented in the (Table 18).

Male headed households are distributed 50 percent in Hlegu area and 66.7 percent in Pathein area. In Hlegu area, 33.3 percent of retailers have bachelors degree while the highest education level in Pathein is the high school level, 33.3 percent. Business experience ranges from 5 to 8 years in Pathein and Hlegu.

As mentioned early, Hlegu area is not too far away from Yangon market and 54.6 percent of retailers mostly buy rice from central wholesaler. 27 percent of them buy rice from local farmers. Pathein retailers buy rice from local farmers, millers and local wholesalers. Almost all retailers set the selling price depending on the buying price of rice. (Table 19) 


\section{CONCLUSION}

This study is based on the data results of survey data 2004 and is characterized the performance of rice farmers and rice traders in the rice marketing channel of the selected areas. From this analysis the following conclusions can be drawn:

The main rice marketing channels in the studied sites indicate that almost all products of farmers flow to collectors and millers. Besides, marketing margin analysis also draw attention to the increasing market power of millers with high profit per investment. Lack of formal cooperative structures, farmers support groups and growing market power of millers at the farm-gate level outcome low bargaining power of farmers in the trading of paddy and rice at the studied areas.

Considerable efforts will also be required at the administrative regional level to ensure a more regular and timely flow of agricultural commodities and trade related data among the regions. The Ayeyarwady Delta plays a very important role in development of agriculture of Myanmar. With a great potential that has not been fully exploited yet, the delta should be paid more attention on the infrastructure process by setting up the appropriate government policies or developing more infrastructures.

In both areas, informal trading networks also share market information among members of the network and personal contacts are the main source of information. Therefore, the available information is not always systematic and reliable due to the variety of sources of market information. To solve the errors that arise from conflicting sources of information a public market information center organized by government and non profit rice traders organization to distribute reliable up-to-date market information effectively and efficiently.

Nowadays, vertical trading networks between rice collectors, millers, brokers, long-distance buyers, wholesalers, and retailers will reduce marketing costs and credit constraints in the marketing systems. This implies that the creation of these networks should be supported by government policy. Agricultural cooperation should be supported and stimulated in order to provide better services for farmers.

In the long run, the complete liberalization of agricultural markets should encourage production on the basis of comparative advantages extended the integration of the economics of administrative regions. Therefore investigating and evaluating the domestic market performance is absolutely necessary to accelerate the market oriented economy. Further study needs to appraise the price fluctuations in each market and price correlation among the central and local rice markets in order to formulate the strategies for the development of the rice marketing efficiency.

\section{REFERENCES}

Central Statistical Organization 2002 Statistical Year Book. Ministry of national planning and economic development. Yangon, Myanmar.

Kohls, R. L., and J. N.Uhi 2002 Marketing of Agricultural Products. $9^{\text {th }}$ edition. Upper Saddle River, N. J.: Prentice Hall. 